\title{
Formation of Reducing Sugars from Sucrose by Erwinia Species
}

\author{
By BARBARA M. LUND \\ Agricultural Research Council Food Research Institute, \\ Colney Lane, Norwich NR4 7 UA
}

(Received 5 August 1974; revised Io February 1975)

\section{INTRODUCTION}

Cultures of Erwinia carotovora var. atroseptica in a sucrose medium accumulate reducing compounds, a property which distinguishes this organism from E. carotovora var. carotovora (Dye, I969a; Graham, 197I). These reducing compounds are mainly the disaccharides palatinose and I-o- $\alpha$-D-glucosyl-fructose (GF) (Lund \& Wyatt, I973). The formation of reducing compounds in a sucrose medium has been used to characterize other species of erwinia (Dye, 1968, 1969a,b,c) but the nature of the compounds formed has not been studied.

In this paper the disaccharides formed by E. carotovora var. atroseptica are shown to account for a substantial proportion of the initial concentration of sucrose. Dye (I968, I $969 a, b, c$ ) found other strains of erwinia which were able to produce reducing compounds from sucrose; a survey is reported of the ability of these strains to form palatinose and GF in the test conditions used by Graham and by Dye.

One of the most useful applications of the test for production of reducing compounds from sucrose, is to distinguish between E. carotovora var. atroseptica and var. carotovora. The possibility has been investigated that failure of E. carotovora var. carotovora to accumulate these compounds may be associated with transient production of palatinose and GF during the exponential phase of growth and subsequent metabolism of these compounds.

\section{METHODS}

Bacteria. The cultures are listed in Table I and include representatives of all the species reported by Dye $(1968,1969 a, b, c)$ to form reducing compounds in a sucrose medium. Erwinia carotovora var. atroseptica $\mathrm{GI} 20$ and strains of E. herbicola, E. tracheiphila and E. rubrifaciens were originally obtained from Dr D. C. Graham, Department of Agriculture and Fisheries for Scotland, Edinburgh. Twelve additional strains of E. carotovora var. atroseptica and three strains of E. carotovora var. carotovora were isolated in this laboratory, and two strains of E. carotovora var. atroseptica were isolated by Dr M. E. Stanghellini, University of Arizona, Tucson, Arizona, U.S.A. The corn-stalk-rot organisms (Dye, I969a) were obtained from Professor R. S. Dickey, Cornell University, Ithaca, New York, U.S.A., and cultures labelled 'Enterobacter agglomerans' were from Dr W. H. Ewing, Centre for Disease Control, Atlanta, Georgia, U.S.A.; the remaining organisms were from the National Collection of Plant Pathogenic Bacteria (NCPPB), Harpenden, Hertfordshire.

Culture media. A medium containing peptone (Difco), I \% (w/v), and beef extract powder (Lab. Lemco), $0.4 \%(\mathrm{w} / \mathrm{v})$, was used, without added sugar (basal medium), with $4 \%(\mathrm{w} / \mathrm{v}$ ) sucrose (sucrose medium) or with $4 \%(\mathrm{w} / \mathrm{v})$ palatinose (palatinose medium).

Test for the production of reducing compounds from sucrose. Cultures were initially screened 
for the ability to accumulate reducing compounds in sucrose medium using the methods of Graham (I97I) and Dye (I968). The bacteria were grown in Io $\mathrm{ml}$ medium in $100 \mathrm{ml}$ flasks at $25{ }^{\circ} \mathrm{C}$ for $48 \mathrm{~h}$ on a shaker (Mark V Orbital Shaker, L.H. Engineering Co., Stoke Poges, Buckinghamshire) with a I inch rotary movement, at'a speed of $250 \mathrm{rev}$. $/ \mathrm{min}$. After incubation, an equal volume of Benedict's solution (qualitative) was added and the culture was heated in a boiling water bath for Io min. Development of a yellow to brown colour was regarded as a positive reaction.

The identity of reducing sugars formed in the sucrose medium. The bacteria were grown in I $00 \mathrm{ml}$ sucrose medium in I 1 flasks at $25^{\circ} \mathrm{C}$ on the rotary shaker at $250 \mathrm{rev}$./min. Samples were removed periodically for measurement of growth in terms of $E_{650}$ and for examination of reducing sugars by chromatography and electrophoresis. For these last analyses the bacteria were removed by centrifugation at $30000 \mathrm{~g}$ for $30 \mathrm{~min}$ at $3{ }^{\circ} \mathrm{C}$ and the culture liquid was stored at $-25^{\circ} \mathrm{C}$. In cultures of $E$. dissolvens NCPPBI 862 and NCPPB2209 and Enterobacter agglomerans biogroup 2, the medium became very viscous; any high molecular weight material was therefore removed by precipitation with 3 volumes of $100 \%$ ethanol. Paper chromatography, paper electrophoresis and spray reagents were as described previously (Lund \& Wyatt, I973), except that the silver nitrate stain used was that of Trevelyan, Proctor \& Harrison (1950) which reacted with reducing sugars and, more slowly, with sucrose. Except when they were present in trace amounts, the identities of palatinose and GF were confirmed by their electrophoretic mobility and formation of characteristic colours with an aniline-diphenylamine spray reagent (Lund \& Wyatt, I973).

Assay of palatinose and GF formed by E. carotovora var. atroseptica GI20. A culture was grown in $100 \mathrm{ml}$ sucrose medium and harvested after $63 \mathrm{~h}$; the $E_{650}$ was 5.5 , equivalent to a dry weight of organisms of about $2.6 \mathrm{~g} / \mathrm{l}$. The bacteria were removed by centrifugation and $30 \mu \mathrm{l}$ samples of the supernatant liquid were analysed by chromatography on Whatman No. I paper for $48 \mathrm{~h}$. After drying the paper, reference strips were cut and stained (Trevelyan et al. 1950) to locate palatinose and GF. Using these strips, areas containing the disaccharides were located and $5 \mathrm{~cm}$ diameter circles containing the sugars were circumscribed with a pencil and compass. The amount of sugar on the discs was estimated directly (Shallenberger \& Moores, 1957) by the method of Somogyi (1952). A standard curve was prepared using palatinose, and allowance was made for interference by the paper.

Examination of cultures of E. carotovora var. carotovora. The bacteria were inoculated into basal medium, sucrose medium and palatinose medium ( 12 or $25 \mathrm{ml}$, in I 50 or $250 \mathrm{ml}$ flasks), and incubated on the rotary shaker. Samples were removed immediately after inoculation, during the exponential phase of growth (at 3, 6, 9 and $12 \mathrm{~h}$ ), and after 24 and $48 \mathrm{~h}$, for measurement of growth by increase in $E_{650}$ and for chromatography.

\section{RESULTS AND DISCUSSION}

Formation of reducing disaccharides by E. carotovora var. atroseptica $\mathrm{GI} 20$

In shaken-flask cultures in sucrose medium at $25^{\circ} \mathrm{C}$, the exponential phase of growth was completed in about $24 \mathrm{~h}$. When samples of cultures taken after incubation for $24,42,48$, 65 and $72 \mathrm{~h}$ were examined by paper chromatography no residual sucrose was detected and the only reducing sugars found were palatinose and GF.

In preliminary assays, recovery of palatinose after chromatography of five replicate samples was $93 \%$. Samples of culture liquid from a $63 \mathrm{~h}$ culture of strain GI 20 contained $5 \mathrm{mg}$ palatinose $/ \mathrm{ml}$ and $9.3 \mathrm{mg} \mathrm{GF} / \mathrm{ml}$ (5 replicate assays), equivalent to 12.4 and $23 \%$ $(w / w)$, respectively, of the initial sucrose concentration. 
Formation of reducing sugars by other species of erwinia

Results of testing $48 \mathrm{~h}$ cultures in sucrose medium with Benedict's reagent are shown in Table I. Cultures which gave a green colour were recorded \pm ; some of these isolates, as well as those giving a clear positive reaction, were examined to determine the identity of the reducing sugars formed. The exponential phase of growth was usually completed after about $24 \mathrm{~h}$ and samples of cultures were removed after $24,42,48,65$ and $72 \mathrm{~h}$. Reducing sugars detected by chromatography of culture filtrates are shown in Table I. In general, where cultures gave a strong reduction in the test with Benedict's reagent, the characteristic reducing sugars had accumulated during the first 24 to $48 \mathrm{~h}$ of growth and the concentrations tended to increase during longer incubation. With strains giving an intermediate reaction (green colour) with Benedict's reagent, glucose and fructose were formed during the first 24 to $42 \mathrm{~h}$ and the concentrations subsequently decreased. Different results may be obtained when these strains are tested for the production of reducing compounds from sucrose in different laboratories, because the rate of growth and metabolism of remaining glucose and fructose will depend on the efficiency of aeration of shaken-flask cultures.

In Table I the species are divided into the four groups distinguished by Dye (1968, I $969 a, b, c)$. In group I organisms (the E. amylovora group) the main reducing sugars formed were glucose and fructose, though unidentified, slow-running compounds, possibly oligosaccharides, were also detected. Two strains of E. amylovora formed a compound, with the same $R_{\mathrm{G}}$ as palatinose, as a minor product and the three cultures of $E$. salicis formed traces of compounds with the same $R_{\mathrm{G}}$ values as palatinose and GF. It is possible that alteration of the growth medium would result in an increased formation of these compounds by strains of E. amylovora and E. salicis. Because of the relatively small amounts formed, these compounds were not isolated, and further tests would be required to confirm their identity.

Of the group 2 organisms, all the $\mathrm{I} 3$ strains of E. carotovora var. atroseptica gave similar results to strain GI20. In cultures of $E$. rhapontici the main reducing sugar formed was palatinose, with a relatively smaller concentration of GF than that formed by strain GI 20; traces of fructose, glucose and slow-running compounds were also detected. Only one strain of E. chrysanthemi and one of the corn-stalk-rot organisms gave a clear positive result with Benedict's reagent; these strains accumulated glucose and fructose in the culture liquid.

Of the group 3 cultures initially screened, only one, E. herbicola 708 , formed palatinose and a small concentration of GF. This was the only strain of E. herbicola among 33 studied by Graham which originated from clinical material, and apart from its metabolism of sucrose this strain resembled the remaining 32 in Ioo tests (D. C. Graham, personal communication). Many clinical isolates of E. herbicola have been studied by Ewing \& Fife ( I972) who termed them 'Enterobacter agglomerans'. Strains representative of the I I biogroups within Enterobacter agglomerans were therefore tested, but none resembled E. herbicola 708 in forming palatinose and GF.

Of the group 4 organisms, two of the three cultures of E. dissolvens formed palatinose and GF as the main reducing sugars, with a lower concentration of GF relative to palatinose than that formed by strain Gr20. The classification of $E$. dissolvens is in some doubt; Dye (I969c) concluded that strains NCPPB I 850 and NCPPBI 862 resembled the genus Klebsiella rather than Erwinia, while Graham (197I) concluded that, apart from being non-motile, NCPPB 1850 resembled Enterobacter cloacae, while NCPPB 1862 resembled Klebsiella aerogenes. Klebsiella aerogenes NCTC4I 8 gave a negative result when tested with Benedict's reagent for the formation of reducing compounds from sucrose, but it would be of interest to know 
Table I. Formation of reducing sugars from sucrose by Erwinia species

Group I

Culture

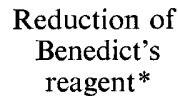
E. amylovora NCPPB683, NCPPB 686
E. amylovora $\mathrm{NCPPB} 7 \mathrm{I} 3, \mathrm{NCPPB} 756$
E. quercina NCPPB I 852 , NCPPBI 853
E. salicis NCPPB447, NCPPBI466, NCPPB23IO
E. tracheiphila 52, Kelman A
E. rubrifaciens $\mathrm{NCPPB} 2020, \mathrm{G} 208$
E. nigrifluens NCPPB564, NCPPB565, NCPPB 566

Group 2

E. carotovora var. atroseptica (14 strains)

E. chrysanthemi

NCPPB453

NCPPB5I 6

NCPPBI 849

E. rhapontici

NCPPB I 39, NCPPBI 578, NCPPBI 739

Corn-stalk-rot organisms SR58, SR59, SR 80 , SR 86

SR87

E. cypripedii $\mathrm{NCPPB} 750, \mathrm{NCPPB} 75 \mathrm{I}$,

$\mathrm{NCPPB} 752$

\section{Group 3}
E. herbicola
NCPPBIO2
G I 42
G708

E. herbicola var. ananas

NCPPB44I

NCPPB 545, NCPPB I 846

E. stewartii NCPPB2293, NCPPB2295

E. uredovora

NCPPB39I

NCPPB 800

NCPPB 4 I 6

Fr

Reducing sugars formed $\uparrow$

Fru Glu Pal GF

Enterobacter agglomerans

Biogroups 5, 6, 7, G2, G3

Biogroups I, 2, GI, G4

Biogroups 3, 4

$\begin{array}{lllll}+ & + & + & \text { TR } & - \\ + & + & + & - & - \\ + & + & + & - & - \\ + & + & + & \text { TR } & \text { TR } \\ + & + & + & - & - \\ + & \text { TR } & + & - & - \\ - & \text { NT } & \text { NT } & \text { NT } & \text { NT }\end{array}$

roup 4

E. dissolvens

NCPPB I 850

NCPPB I 862, NCPPB2209

E. nimipressuralis

NCPPB440, NCPPB2045

$\begin{array}{ll}+ & \\ - & \\ + & \\ + & \\ \pm & \\ - & \\ & \\ \pm & \\ \pm & \\ \pm & \\ - & \\ - & \text { TR } \\ \pm & \end{array}$

\section{TR}

$\begin{array}{ll} \pm & \text { TR } \\ \pm & \text { NT } \\ + & +\end{array}$

TR

NT

NT

NT

$+\quad \mathrm{TR}$

$\pm \quad T R$

$+\quad+$

$+\quad+$

NT

NT

NT

NT

, Intermediate reaction (green colour) with Benedict's reagent; TR, trace; NT, not tested.

* Tested after $48 \mathrm{~h}$ incubation at $25^{\circ} \mathrm{C}$ in shaken flasks of sucrose medium.

$\uparrow$ Detected by chromatography of culture liquid after 24 to $72 \mathrm{~h}$ in sucrose medium. Fru, fructose; glu, glucose; pal, palatinose; GF, I-o- $\alpha$-D-glucosyl-fructose. 
whether the ability to form palatinose and GF is found widely among different genera of the Enterobacteriaceae.

\section{Examination of cultures of E. carotovora var. carotovora}

When three strains of this organism were grown in sucrose medium, neither palatinose nor GF could be detected on chromatograms of culture samples taken after 3, 6, 9, I 2, 24 or $48 \mathrm{~h}$ incubation. Traces of glucose and fructose were detected in cultures grown for up to $24 \mathrm{~h}$ but not after $48 \mathrm{~h}$. When these strains were grown in palatinose medium for up to $48 \mathrm{~h}$ no disappearance of palatinose or formation of glucose or fructose could be detected by chromatography. The growth of bacteria in palatinose medium was equivalent to that in the basal medium. Substitution of sucrose for palatinose resulted in an increase of between 3- and 5 -fold in growth of the bacteria. The results with these three strains indicate that failure of cultures of $E$. carotovora var. carotovora to accumulate palatinose and GF was not due to metabolism of these compounds.

I am grateful to Dr D. C. Graham, Dr W. H. Ewing, Professor R. S. Dickey and Dr M. E. Stanghellini for supplying cultures, and to Mrs P. M. Yeates for excellent technical assistance.

\section{REFERENCES}

DyE, D. W. (I968). A taxonomic study of the genus Erwinia. I. The 'Amylovora' group. New Zealand Journal of Science II, 590-607.

DyE, D. W. (1969a). A taxonomic study of the genus Erwinia. II. The 'Carotovora' group. New Zealand Journal of Science 12, 81-97.

Dye, D. W. (1969b). A taxonomic study of the genus Erwinia. III. The 'Herbicola' group. New Zealand Journal of Science 12, 223-236.

Dye, D. W. (1969c). A taxonomic study of the genus Erwinia. IV. 'Atypical' erwinias. New Zealand Journal of Science 12, 833-839.

EwING, W. H. \& Fife, M. A. (1972). Enterobacter agglomerans (Beijerinck) comb. nov. (the HerbicolaLathyri bacteria). International Journal of Systematic Bacteriology 22, 4-1 I.

Graham, D. C. (1971). Identification of soft rot coliform bacteria. In Proceedings of the Third International Conference on Plant Pathogenic Bacteria, pp. 273-279. Edited by H. P. Maas Geesteranus. Wageningen: Centre for Agricultural Publishing and Documentation.

LUND, B. M. \& WyatT, G. M. (1973). The nature of reducing compounds formed from sucrose by Erwinia carotovora var. atroseptica. Journal of General Microbiology 78, 33I-336.

Shallenberger, R. S. \& Moores, R. G. (1957). Quantitative determination of reducing sugars and sucrose separated by paper chromatography. Analytical Chemistry 29, 27-29.

Somogyi, M. (1952). Notes on sugar determination. Journal of Biological Chemistry 195, 19-23.

Trevelyan, W. E., Proctor, D. P. \& Harrison, J. S. (1950). Detection of sugars on paper chromatograms. Nature, London 166, 444-445. 